\title{
AN EPIDEMIOLOGIC STUDY OF DRUG ABUSE AND HIV AND AIDS IN MALAWI
}

\section{Thomas Bisika, ${ }^{1,2}$ Sidon Konyani, ${ }^{2}$ Immaculate Chamangwana, ${ }^{3}$ George Khanyizira ${ }^{4}$}

${ }^{1}$ University of Pretoria, School of Health Systems and Public Health, ${ }^{2}$ Centre for Social Research, University of Malawi, ${ }^{3}$ Zomba Mental Hospital, Ministry of Health, ${ }^{4}$ Zomba Central Hospital, Ministry of Health

\begin{abstract}
In this study we examine the prevalence of HIV among drug abusers in Malawi. A purposive sample of 200 drug abusers was invited to provide urine and blood samples. The subjects were selected from self-presenting drug abusers who visited a district hospital in Malawi. The urine samples from both men and women were tested for Gonorrhea and Chlamydia. Urine samples from women were also tested for pregnancy. The blood samples were tested for HIV. The study found a higher prevalence of HIV among non-injecting drug abusers, with those who abused alcohol being more likely to be HIV positive as compared to cannabis abusers. Prevalence of sexually transmitted infections (STIs) was, however, low. The main conclusion from this study is that drug abuse is a risk factor for HIV and not as much for STIs, even in non-injecting drug abusers.
\end{abstract}

KEY WorDS: Malawi, drug abuse, cannabis, HIV epidemiology, non injecting drug use, sexually transmitted infection

\section{INTRODUCTION}

More than 40 million people are living with HIV worldwide, including 5 million new cases in 2005 alone, with Africa contributing about 25 million (UNAIDS, 2006). Malawi is one of the countries worst hit by the HIV and AIDS epidemic with an infection rate among the childbearing age group of $16.4 \%$. Youth aged 15-24 claim $46 \%$ of new HIV infections of which $60 \%$ occur among girls. It is estimated that about 735,000 people are sero-positive of which 265,000 have already developed AIDS (Malawi National AIDS Commission, 2003).

There are three main drugs of abuse in Malawi, namely alcohol, cannabis and tobacco (cigarettes). The most common drug of abuse in Malawi is cannabis. Its consumption is growing and production had increased from 170,000 hectares in 1999 to 175,000 in 2000. Cannabis use in Malawi is still encouraged by traditional beliefs, such as women's belief that cannabis can cure measles, some students believe that it can make them intelligent and some men think that cannabis can improve their sexual potency. There has been an increase in drug abuse cases in Malawi, from 15\% in 1995 to $21 \%$ in 1999 . It has also been observed that the problem of drug abuse, especially cannabis is increasing among the youth resulting in an annual average of $20 \%$ of registered mental illness cases

* Corresponding author: Dr. Thomas Bisika, Senior Lecturer, University of Pretoria School of Health Systems and Public Health, Pretoria, South Africa. E-mail: thomas.bisika@up.ac.za 
and other related diseases (Bisika et al, 2004).

Drug abuse and addiction have been linked with HIV and AIDS since the beginning of the epidemic. Although injection drug use is well known in this regard, the role that non-injection drug abuse plays in the spread of HIV is less recognized. Drugs have addictive and intoxicating effects, which can alter judgment and inhibition and lead people to engage in impulsive and unsafe behaviors. Studies in several countries have shown an association between harmful consumption of alcohol and health and social consequences, including death from road traffic accidents, domestic violence, HIV infection, and disorders requiring demand for treatment (Obot, 2006).

People typically associate drug abuse and HIV and AIDS with injection drug use and needle sharing. When injection drug users (IDUs) share equipment, such as needles, syringes, and other drug injection paraphernalia, HIV can be transmitted between users. Other infections, such as hepatitis $\mathrm{C}$, can also be spread this way. Hepatitis C can cause liver disease and permanent liver damage. Studies have observed that HIV rates are higher among Aboriginal IDUs as compared to the aboriginal general population (Remis, 2000) and that IDUs have been pivotal in the dynamics of the HIV epidemic (Bastos et al, 2002). Studies have also documented a serious concentrated HIV epidemic among IDUs in countries like Mauritius (Abdool et al, 2006). There are, however, studies that show that HIV rates obtained for IDUs and non injection drug users (NIDUs) are fairly similar (Adelekan, 2006).

Behaviors associated with drug abuse are among the main factors in the spread of HIV infection. Drugs can change the way the brain works through disrupting the parts of the brain that people use to weigh risks and benefits when making decisions (National Institute on Drug Abuse, 2007). Poor judgment and risky behavior also predisposes drug abusers to HIV. Drug abuse by any route (not just injection) can put a person at risk for contracting HIV because drug and alcohol intoxication affect judgment and can lead to unsafe sexual practices, which put people at risk for contracting HIV or transmitting it to others. Studies elsewhere have shown that women who use crack-cocaine risk HIV transmission through unprotected sexual exchange (Lichtenstein, 1997). Moreover, many women believe that crack-cocaine and heroin enhance a man's sexual desire, performance and pleasure and that the same drugs are responsible for their partner's abusive and coercive behaviour (El-Bassel et al, 2003).

Biological effects of drug abuse and addiction can affect a person's overall health, thereby altering susceptibility to HIV and progression of AIDS. Drugs of abuse and HIV both affect the brain. Research has shown that HIV causes greater injury to cells in the brain and cognitive impairment among methamphetamine abusers than among HIV patients who do not abuse drugs. In animal studies, methamphetamine has been shown to increase the amount of HIV in brain cells (National Institute on Drug Abuse, 2007). However, there are some studies that have demonstrated that cannabis does not harm the health of the consumers (The Lancet Editorial, 1995) while others have concentrated on the medical use of cannabis among AIDS patients and its potential to improve quality of life and health care outcomes among patients with HIV and AIDS(Prentiss et al, 2004; Ware et al, 2003).

The main objective of this study was to document the nature and extent of the HIV epidemic among drug abusers in 
Malawi. The specific objectives were to identify the actual drugs of abuse and the associated method of use, determine the prevalence of HIV among drug abusers, measure the magnitude of the STI problem in drug abusers and document the prevalence of pregnancy among female drug abusers.

\section{METHOD}

\section{Sampling}

As part of a larger HIV and AIDS and Drug Abuse assessment study which was conducted by the Centre for Social Research of the University of Malawi in collaboration with the Ministries of Health and Home Affairs with funding from United Nations Office for Drug Control (UNODC), a sample of $200 \mathrm{drug}$ abusers was invited to provide urine and blood samples. These were selected from self-presenting drug abusers who visited a district hospital in Malawi in June 2004. All the biological specimens were collected in Thyolo district located in the Southern Region of Malawi. For the purposes of this study, besides narcotic drugs, cannabis, tobacco and alcohol were also included as drugs of abuse and drug abuse was defined as the use of any drug of abuse at least on a monthly basis.

\section{Procedures and measurement}

Field workers who were undergraduate students were supplied with a shoulder cooler bag, specimen containers, plastic bag and gloves for collection of urine. These field workers underwent a one week training which was facilitated by a laboratory assistant and a registered nurse/midwife. Two of the fieldworkers were male while one was female. For women, first-voided morning specimens were preferred for pregnancy testing of maximal hCG concentration, but those collected any other time were still tested. Each specimen was labeled with the subject's identification number to ensure confidentiality. A short questionnaire was used to collect drug use, social and demographic data. The drugs listed on the questionnaire included cannabis, alcohol, cocaine, Mandrax, Valium and tobacco. The study subjects were asked if they had used any drug of abuse in the 30 days preceding the survey. Drugs of abuse were captured as a multiple-response variable which means that a drug abuser could mention more than one drug of abuse.

The urine samples for both men and women were tested for Gonorrhea and Chlamydia (for women, they were also tested for pregnancy). The blood samples were tested for HIV. The urine samples were sent to University of North Carolina (UNC) Laboratory in Lilongwe, Malawi where a technician tested them for Gonorrhea and Chlamydia using a PCRbased test. The urine samples from female subjects were tested for pregnancy. The Betatex Direct Plus Kit, a direct latex agglutination test produced by Omega Diagnostics Ltd., was used for in-vitro detection of $\mathrm{hCG}$ in urine. Physical condition of pregnancy was indicated by positive agglutination with hCG concentration of $0.2 \mathrm{IU} / \mathrm{ml}$ or higher. A rapid diagnostic test called Determine was used for HIV testing on the spot. The HIV testing was done using the existing HIV testing guideline which requires that study subjects under the influence of drugs should be excluded.

\section{Data Analysis}

Tabulation of the data and further analysis was done using the Statistical Package for Social Scientists (SPSS) and Epi-info.

\section{Ethical Consideration}

All biological specimens were collected with full privacy along with the 
interviews. Bio-specimens did not have names indicated, they were labeled by a respondent identification number and all information collected during the interviews was treated as confidential all the time. The purpose of the study was explained to the participants and the use of biological specimens was also clarified to the respondents before obtaining a verbal informed consent which was preferred due to the sensitivity of the topic that was being studied. Urine and blood was only collected from those respondents who agreed. Respondents who were under the influence of drugs at the time of specimen collection were excluded from the study.

All respondents with STIs were treated with a single dose of Ciproflaxin (for Gonorrhea in males) and $100 \mathrm{mg}$ of Doxycycline taken twice daily for 7 days for male Chlamydia cases. All infected women were supplied with 500 mg of Erythromycin taken 4 times daily for 7 days. All non-infected individuals were given a dose of Vitamin C of 500 $\mathrm{mg}$ for 7 days in order to cover those who were infected from being identified. The District Health Office was given the authority to treat the patients with STIs using Malawi government approved protocols as an option. Those who tested positive for HIV were offered post-test counseling and linked to existing AIDS service organizations for on-going counseling and treatment. The proposal was submitted to National Health Sciences Research Committee for ethical review. An approval was received on December 29, 2003 (Ref: 05/5G).

\section{RESULTS}

\section{Socio-demographic background}

Out of the 200 participants recruited, 191 were male. With respect to age, most of the study subjects were in their twenties. The dominant tribe was Lomwe $(56.0 \%)$ followed by Mang'anja (20.5\%). Most of the participants had only primary education (129 out of the 200) while $30 \%$ had secondary education. Only 6 participants out of the $200(3 \%)$ had tertiary education. The study subjects were mainly migrant tea estate workers $(43 \%)$ and self employed (28\%) and the most predominant religion was protestant $(69 \%)$ followed by Catholic $(21 \%)$. Islam accounted for $8 \%$ only (Table 1).

Table 1. Social and demographic characteristics of the sample $(\mathrm{N}=200)$

\begin{tabular}{|c|c|c|}
\hline Attribute & & Percentage \\
\hline \multicolumn{3}{|l|}{ Gender } \\
\hline & Male & 95.5 \\
\hline & Female & 4.5 \\
\hline \multicolumn{3}{|l|}{ Age } \\
\hline & Under 20 & 3.1 \\
\hline & $20-28$ years & 46.9 \\
\hline & 29-39 years & 27.1 \\
\hline & $40-49$ & 14.2 \\
\hline & Over 50 years & 7.7 \\
\hline \multicolumn{3}{|l|}{ Tribe } \\
\hline & Lomwe & 56.0 \\
\hline & Mang'anja & 20.5 \\
\hline & Yao & 7.0 \\
\hline & Ngoni & 5.0 \\
\hline & Chewa & 4.0 \\
\hline \multicolumn{3}{|l|}{ Religion } \\
\hline & Protestant & 69.3 \\
\hline & Catholic & 20.9 \\
\hline & Islam & 8.4 \\
\hline \multicolumn{3}{|l|}{ Education } \\
\hline & None & 2.3 \\
\hline & Primary & 64.5 \\
\hline & Secondary & 30.2 \\
\hline \multirow{2}{*}{\multicolumn{3}{|c|}{ Occupation }} \\
\hline & & \\
\hline & Employed & 43.2 \\
\hline & Business & 27.7 \\
\hline & Farmer & 11.3 \\
\hline & Unemployed & 9.8 \\
\hline
\end{tabular}




\section{HIV and STI epidemiology}

The overall prevalence rate for HIV was $25.5 \%$ which was three times higher than both the district $(7.7 \%)$ and almost twice national $(14.4 \%)$ prevalence. The drugs of abuse mentioned by the participants were cannabis (chamba) $(81.3 \%)$ and alcohol $(18.3 \%)$. $(\mathrm{N}=246)$. Methods of use included smoking (78.9\%), drinking (19.9\%) and sniffing $(1.2 \%)$. $(\mathrm{N}=251)$. A close look at the HIV prevalence rate by type of drug abuse revealed that more than a quarter of the respondents $(25.5 \%, 95 \% \mathrm{CI}=20.5$ $31.5 \%$ ) who abused cannabis were seropositive while close to a third $(31.1 \%$, $95 \% \mathrm{CI}=25.2-36.8 \%)$ of alcohol abusers were positive. This difference was not statistically significant using either a 1tail or 2-tail Z-test.

With respect to the method of use, more than two thirds $(66.7 \%, \mathrm{~N}=3)$ of those who reported sniffing were seropositive, about a third of those who reported drinking as a method of use were also sero-positive. More than a quarter of those who cited smoking as their mode of use were HIV positive. There were no injection drug users in the sample. (Table 2).

Table 2. HIV prevalence among drug abusers

\begin{tabular}{lc}
\hline Category & \%Prevalence $(95 \% \mathrm{CI})$ \\
\hline Overall & $25.5(19.5-31.5)$ \\
Cannabis abusers & $25.5(20.5-31.5)$ \\
Alcohol abusers & $31.1(25.2-36.8)$ \\
& \\
Method of use & \\
Sniffing (N=3) & 66.7 (Undefined)* \\
Drinking & $30.4(24.3-35.7)$ \\
Smoking & $25.3(19.6-30.4)$ \\
\hline
\end{tabular}

*Only three cases reported sniffing

Although HIV and AIDS awareness is almost universal in Malawi, most of the drug abusers recruited in this study did not know the relationship between drug abuse and HIV and AIDS (57.8\%).

With respect to STIs, there was only one case of Gonorrhea. This case was male and was also an HIV case. Less than $10 \%$ ( 1 in 9$)$ of the women in the sample were pregnant $(\mathrm{N}=9)$.

\section{DISCUSSION}

Cannabis (chamba) was the most common drug of abuse while smoking was the commonest method of use. Although there were no injection drug users among the study subjects, HIV prevalence was much higher among drug abusers than in the corresponding general population. This means that there was indeed an ecological relationship between HIV and AIDS and drug abuse, that is, HIV and drug abuse thrive in the same environment. This is consistent with what was found by other researchers in South America (Olukoga, 2004).

Alcohol abusers had an excess risk for HIV as compared to Cannabis (chamba) abusers. This could be due to the fact that alcohol is imbibed in places where prostitutes transact their business. It must be noted, however, that both alcohol and Cannabis (chamba) abusers had a heightened risk for HIV and AIDS. Most of the participants did not know the relationship between HIV and AIDS and drug abuse. It is, therefore, very important to highlight the ecological relationship between drug abuse and HIV infection in national HIV and AIDS prevention and sensitization campaigns.

No injecting drug abusers were in the sample. This shows that high seroprevalence is not only associated with injecting drugs use. Thus drug abuse by any route (not just injection) can put a person at risk for getting HIV. This finding is not at variance with what was 
concluded in a study conducted in Nigeria $^{8}$. The results obtained on STI prevalence does not support the direct linkage of STIs and drug abuse but underscores the fact that drug abusers have a higher risk for HIV than STIs. This inverse relation was also observed in another study which concluded that higher socioeconomic status was a risk factor for HIV-1 infection but not for STIs (Dallabetta et al, 1993). Since our study was conducted at a health facility, further population based research is required to investigate the low prevalence of STIs among drug abusers as this might mean that most of them are not seeking treatment from hospitals.

The major limitation of this study was the small representation of women and youth which has implications on the representativeness of sample and hence external validity of the findings. The other problem was that data on marital status was not collected and it was, therefore, not possible to control for marital status as a confounding factor. Similarly the researchers did not collect information on risk factors and sexual behaviour. These could have helped to further explain the findings.

\section{CONCLUSION}

A higher HIV prevalence was observed among non injecting drug abusers as compared to the district and national prevalence. The prevalence of STIs was, however, low. This indicates that non injecting drug use is a risk factor for HIV but not STIs. While HIV and AIDS awareness remains high in the general population, the low knowledge regarding the linkage between drug abuse and HIV and AIDS requires an intervention of a public health nature including targeting drug abusers in VCT campaigns.

\section{REFERENCES}

Abdool, R., Sulliman, F.T. and Dhannoo, M.I. (2006). The injecting drug use and HIV/AIDS nexus in the Republic of Mauritius. African Journal of Drug and Alcohol Studies, 5(2), 107-116.

Adelekan, M.L. and Lawal, R.A. (2006). Drug use and HIV Infection in Nigeria: a review of recent findings. African Journal of Drug and Alcohol Studies, 5(2), 117-128.

Bastos, F.I., de Fatima de Pina, M. and Szwarcwald, C.L. (2002). The social geography of HIV and AIDS among injection drug users in Brazil. International Journal of Drug Policy, 13(2), 18-20.

Bisika, T., Konyani, S. and Chamangwana, I. (2004). Rapid Situation Assessment of Drug Abuse and HIV and AIDS in Malawi. Centre for Social Research, University of Malawi.

Dallabetta, G.A., Miotti, P.G., Chiphangwi, J.D., Saah, A.J. and Liomba, G. (1993). High socioeconomic status is a risk factor for human immunodeficiency virus type 1 (HIV-1) infection but not for sexually transmitted diseases in women in Malawi: implications for HIV-1 control. Journal of Infectious Diseases, 167(1), 36-42.

El-Bassel, N., Gilbert, L. and Rajah, V. (2003). The Relationship between drug abuse and sexual performance among women on methadone. Heightening the risk of sexual intimate violence and HIV. Addictive Behaviours, 28(8), 1385-1403

Lichtenstein, B. (1997). Women and CrackCocaine Use: A study of social networks and HIV risk in an Alabama jail sample. Addiction Research, 5(4), 279-296.

Malawi National AIDS Commission. (2003). National Estimate of HIV and AIDS in Malawi. Lilongwe, Malawi.

National Institute on Drug Abuse (NIDA). (2007). How are drug abuse and HIV and AIDS related? Available at http:/hiv.drugabuse.gov/english/learn/ab use.html accessed on November 21, 2007.

Obot, I.S. (2006). Alcohol use and related problems in sub-Saharan Africa. African 
Journal of Drug and Alcohol Studies, $5(1), 17-26$.

Olukoga, I.A. (2004).Epidemiologic trends of HIV/AIDS in Jamaica. Rev Panam Salud Publica, 15(5), 358-63.

Prentiss, D., Power, R., Balmas, G., Tzuang, G. and Israelski, D.M. (2004). Patterns of Marijuana Use Among Patients With HIV and AIDS Followed in a Public Health Care Setting. JAIDS Journal of Acquired Immune Deficiency Syndromes, 35(1), 38-45.

Remis, R.S. (2000). HIV incidence among injecting drug users in Vancouver. JAMC, 162(5), 33-37.
The Lancet Editorial. (1995) Deglamorizing Cannabis. The Lancet, 346(8985).

UNAIDS. 2006. 2006 Report on the global AIDS epidemic

Ware, M., Rueda, S., Singer, J. and Kilby, D. (2003). Cannabis use by persons living with HIV and AIDS: patterns and prevalence of use. Journal of Cannabis Therapeutics: Studies in Endogenous, Herbal, and Synthetic Cannabinoids Official journal of the International Association for Cannabis as Medicine, 3(2), 3-15. 